\title{
Competition and subsequent risk-taking behaviour: Heterogeneity across gender and outcomes और
}

\author{
Antonio Filippin ${ }^{\mathrm{a}, \mathrm{b}}$, Francesca Gioia ${ }^{\mathrm{c}, \mathrm{d}}$ \\ ${ }^{a}$ University of Milan, Department of Economics, Via Conservatorio 7, 20122 Milano, Italy \\ ${ }^{b}$ Institute for the Study of Labor (IZA), Schaumburg-Lippe-Str. 5-9, 53113 Bonn, Germany \\ 'University of Milan, Department of Law 'Cesare Beccaria,' Via Festa del Perdono 7, 20122 Milano, Italy \\ ${ }^{d}$ The University of Edinburgh, School of Economics, 30 Buccleuch Place, Edinburgh, EH8 9JT, UK
}

\begin{abstract}
This paper studies if competition affects subsequent risk-taking behaviour by means of a laboratory experiment that manipulates the degree of competitiveness of the environment under equivalent monetary incentives. We find that competition increases risk aversion, especially for males, but not in a significant manner. When conditioning on the outcome, we find that males become significantly more risk averse after losing the tournament than after randomly earning the same low payoff. In contrast, males do not become more risk-seeking after winning the tournament, while females' average risk-taking behaviour is unaffected by tournament participation and outcomes. Our findings can be rationalized using the results of the literature on self-serving attribution.
\end{abstract}

\section{JEL Classifications: C81; C91; D81}

Keywords: Competition, Risk attitudes, Gender

\section{Introduction}

People compete for better paid jobs, for career advancements, for mates, and for monetary and non-monetary rewards. In general, competition is widely used as incentive scheme and constitutes an important motivating device especially in situations where measuring absolute performance is difficult, for instance when shocks affect productivity or when performance evaluation is subjective. The fact that risk attitudes and competitiveness may correlate is rather intuitive, as tournaments typically imply uncertain outcomes. Thus, the decision to enter the competition and the behaviour in a competitive environment are naturally influenced by subjects' risk attitudes.

In this paper we go one step further analysing the possible consequences of competitive endeavours on risk attitudes. Tournaments require agents to think strategically about

\footnotetext{
We would like to thank Michele Belot, Steven Dieterle and participants to the ASFEE 2016, IMEBESS 2016, ESA 2016 and SEET 2017 conferences for useful suggestions. All remaining errors are ours. Francesca Gioia gratefully acknowledges financial support from Economic and Social Research Council.

Contact: antonio.filippin@unimi.it (Antonio Filippin), f.gioia@sms.ed.ac.uk (Francesca Gioia)
} 
their competitors' effort and decisions (Bull et al., 1987), something that induces a great deal of uncertainty on the final payoff even conditioning on the agent's own performance. We conjecture that being exposed to such an uncertainty while competing may have carryover effects on subsequent (and unrelated) decisions under risk.

Given the novelty of our research question, there is not an established theory in the literature suggesting a possible transmission mechanism. However, some variables have been shown to be a consequence of competitive endeavours on the one hand and to shape risk preferences on the other hand, thereby constituting potential transmission mechanisms. ${ }^{1}$ First, the competitive pressure and the additional effort required by strategic uncertainty triggers fatigue and stress (Buckert et al., 2015; Zhong et al., 2016), factors that have been shown to induce more conservative decisions under risk (Deck and Jahedi, 2015; Starcke and Brand, 2012). Second, outcomes based on competition may also trigger a set of different emotions and feelings (Cerin and Barnett, 2006; Kräkel, 2008). Subjects feel joy and pride when outperforming their opponent, whereas they feel sadness, disappointment, and anger when falling behind. Drichoutis and Nayga Jr (2013) find that negative moods tend to increase risk aversion for choices consistent with Expected Utility Theory, but results in the literature are indeed mixed. ${ }^{2}$ Third, subjects performing in a competitive environment know that the outcome is not a pure chance event because their ability and effort also matter. How subjects weight the role played by their characteristics with that played by luck may have carry-over effects. The self-serving attributional bias (Deaux and Farris, 1977) is defined as the tendency of individuals to make attributions for negative outcomes that are more external than for positive ones. Beisswingert et al. (2016) indeed show that exogenously shifting the locus of control from internal to external induces a more risk averse behaviour. Hence, subjects may become more risk averse after losing the tournament because of a shift in their locus-of-control.

Whatever the cause, investigating whether the competitiveness of the environment can in turn shape subsequent decisions under risk is important because the analysis of competition is usually focused only on its immediate effects on productivity. Competition as a one-shot phenomenon is mainly an abstraction of laboratory experiments, while choices are usually taken in situations where competition occurs repeatedly or is followed by other decisions. ${ }^{3}$ Hence, besides short-run effects on performance, the exposure to competition may

\footnotetext{
${ }^{1}$ There is a growing literature showing that risk attitudes are shaped by life experiences and by the characteristics of the environment rather than innate and immutable. For instance, Booth and Nolen (2012) find that women's risk preferences react to the gender composition of the education environment. Cameron and Shah (2015) and Botchway (2018) show that people exposed to extreme weather events exhibit a long-lasting increase of risk aversion, while an opposite reaction is reported by Eckel et al. (2009) in the aftermath of Hurricane Katrina.

${ }^{2}$ Conte et al. (2013) find that four emotional states (joviality, sadness, fear, and anger) induce risk-seeking behaviour. As far as anger is concerned these results are in line with Lerner and Keltner (2001), who instead display that fear increases risk aversion. Sadness increases risk aversion according to Campos-Vazquez and Cuilty (2014). Lane (2017) highlights inconclusive evidence of happiness in a review of the literature.

${ }^{3}$ Gill and Prowse (2014) study how the outcome of competition affects the productivity of men and women in subsequent competitive interactions. They find that for women losing per se is detrimental to productivity, while for men such an effect is observed only when the prize at stake is big enough. Haenni (2016) finds in a sample of amateur tennis players that it takes on average $10 \%$ longer to compete again after losing than after winning.
} 
have long-run consequences and the change in risk attitudes may constitute a transmission mechanism.

We answer our research question through a laboratory experiment in which competition occurs in the Coin Task (Gioia, 2016), a real effort task that consists in recognizing the value and the country of Euro coins. We measure participants' risk preferences by using the Bomb Risk Elicitation Task (Crosetto and Filippin, 2013), where subjects have to choose how many boxes to collect out of 100, 99 of which contain 10 Euro cents while one contains a bomb that destroys the earnings. We compare the risk preferences in a treatment in which the rewards in the Coin Task are determined in a tournament against a baseline condition where comparable payoffs are instead predetermined. Such a (between-subject) design allows us to control for another reason why competition may affect subsequent risk taking, namely social comparison.

We also aim at investigating whether the relationship between the competitiveness of the environment and risk attitudes is different for men and women. Some contributions in the literature claim that women are more risk averse than men (Croson and Gneezy, 2009; Eckel and Grossman, 2008) although the estimated gender difference in risk attitudes depends on the method used to measure risk attitudes (Filippin and Crosetto, 2016). On the other hand, at least since Niederle and Vesterlund (2007) it has been shown that women tend to shy away from competition. ${ }^{4}$ The combination of these two strands of the literature has even suggested that unequal outcomes in the labour market may be rationalized by higher risk aversion of women (Booth and Nolen, 2012). However, while gender differences in fondness for competition and in performance in competitive situations have been largely replicated (see Böheim and Lackner, 2013; Gneezy et al., 2003; Niederle and Vesterlund, 2011; Vugt et al., 2007, among the others), the role played by risk attitudes has been investigated showing mixed results. Some contributions find that most of the gap can be explained by gender differences in attitudes towards competition, while risk preferences have only a limited impact (Buser et al., 2014; Niederle, 2016; Saccardo et al., 2017). Other papers instead show that risk attitudes and confidence can explain most of the gender competitiveness gap (Apicella et al., 2017; Gillen et al., 2015; van Veldhuizen, 2016).

In light of this evidence, we believe that it is worth investigating whether competition affects risk preferences differently for men and women. For example, if women are both more risk averse and less willing to engage in competition than men, after being exposed to the risk of a competitive endeavour they may be more likely to avoid further - although independent - risk. Similarly, since men like competition more and tend to perform better, after the competitive experience, they may be more likely to take on further risk.

Our results suggest that competition does not affect risk-taking behaviour on average. Performing the Coin Task in a tournament slightly increases risk aversion as compared to the baseline condition, but not significantly so. When investigating gender heterogeneity, we find that the slightly higher level of risk aversion after the tournaments is driven by a potentially important effect for males, whose difference in the choice under risk across treatments is quite large though not significant at conventional levels. In fact, interesting

\footnotetext{
${ }^{4}$ Most of the research on gender differences in willingness to compete has focused on competitions against others. In competitions against one's own previous performance when a lower degree of risk is involved no gender difference emerges (Apicella et al., 2017).
} 
evidence emerges when disaggregating the results by both gender and outcomes. Males become significantly more risk averse after losing the tournament than after earning the same payoff in the baseline treatment. There is instead no evidence of a more risk-seeking behaviour after winning the tournament. As regards females, their risk attitudes are unaffected by participating in the tournament and by its outcome.

Although our experiment was not designed to empirically test the possible transmission mechanisms against each other, the pattern of observed results is better rationalized by a shift in the locus of control from internal to external caused by losing the tournament, while we tend to exclude the other explanations. On one hand, observing an effect on risk attitudes conditional on the outcome of the tournament casts a shadow of skepticism over stress and fatigue, because they should characterize winners and losers alike. On the other hand, the gender differences observed do not have a counterpart in the literature on emotions and risk attitudes. Our results are instead consistent with the literature on self-serving attributional bias claiming that individuals tend to make attributions for negative outcomes that are more external than for positive ones. Losing the tournament causes a shift in the locus of control that, in turn, induces a more risk averse behaviour (Beisswingert et al., 2016). We observe an heterogeneous effect by gender because the self-serving attributional bias tends to affect males and females differently. Deaux and Farris (1977) were the first showing that males are more prone than females to such a bias, a result confirmed by several studies, as described in the meta-analysis by Mezulis et al. (2004). Losing the tournament reduces the extent to which males believe that they can predict or influence future outcomes, thereby increasing their risk aversion.

Up to our knowledge, very few contributions in the literature are related to the effect of competition on subsequent decisions under risk. Gioia (2016) studies the impact of peer effects on risk-taking behaviour under different incentive schemes, including tournaments. She finds that competition more than halves the magnitude of peer influence on a subsequent individual decision under risk, but its effect does not reach statistical significance. Apicella et al. (2014) study the effect of changes in the level of testosterone induced by winning or losing a rock-paper-scissors tournament on subsequent willingness to take risk. They report an increase in testosterone levels after the tournament, higher for winners than for losers, and greater for subjects who win by a tighter margin. The authors find that testosterone significantly correlates with the decision of taking more risk in a multiple price list task. However, Apicella et al. (2014) do not study the behaviour of females and their task is based on pure chance, while ability and effort do not matter. Finally, Buser (2016) studies the effect of competition on the willingness to seek further challenges. He finds that when subjects perform at the individual level the same task (adding two-digit numbers) in which they have previously lost in a winner-takes-all tournament, they tend to set a higher performance target to meet for payment but also to perform worse. In Buser (2016) risk attitudes act as a mediator between competition and the decisions in the second stage. However, decisions also depend on ability and effort, which instead do not play any role in our setting as we administer a pure risk task.

The structure of the paper is as follows. Section 2 describes the tasks adopted as well as the experimental design and procedures. In Section 3 we present the results of the experiment, first at the aggregate level and then disaggregated by gender and outcome in the tournament. Section 4 concludes. 


\section{Experimental design}

The experiment entails the exogenous manipulation of the degree of competitiveness of a real effort task performed before eliciting subjects' risk preferences. We implement two conditions in a between-subject design: a treatment in which the rewards in the real effort task are decided by a tournament within pairs of subjects (Competition), and a control condition in which comparable payoffs are instead exogenously assigned (Baseline).

The real effort task that subjects perform is the Coin Task (Gioia, 2016). The Coin Task consists in recognizing the value and the country of Euro coins. Participants see on the lefthand side of their computer screen a table with Euro coins of different values from several countries, and on the right-hand side a coin randomly drawn from the table (see Figure 1). The task of the subjects is to identify the value and the country of the selected coin. After the answer is submitted, a new table and a new coin to identify appear on the subject's screen. Participants have five minutes to recognize as many coins as possible. The score is the number of coins successfully recognized, with no penalty for wrong answers.

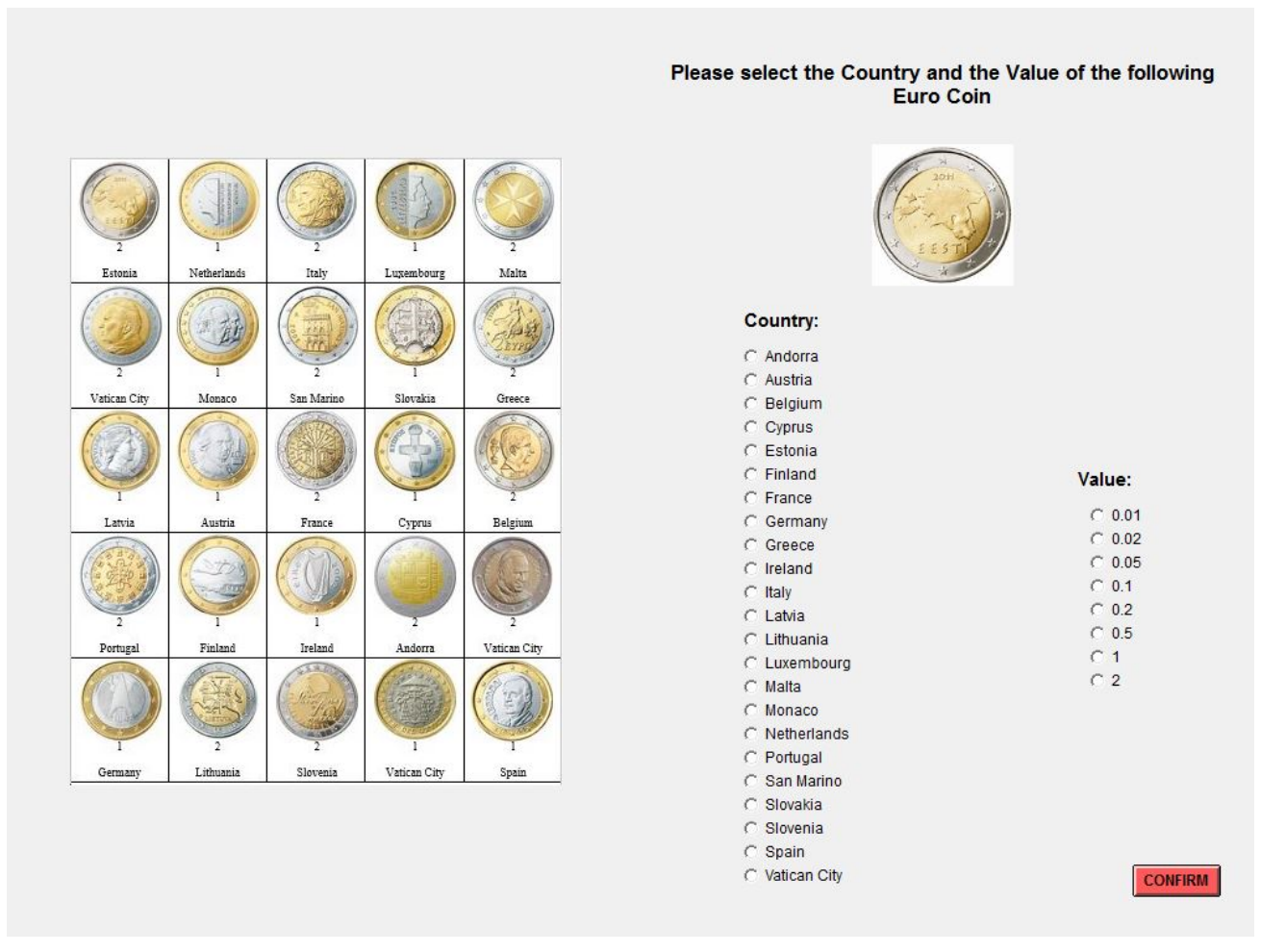

Figure 1: The Coin Task

The main advantage of the Coin Task in comparison to other real effort tasks is that all subjects may provide correct answers if they exert enough effort. Ability or knowledge may of course help to be faster and to suffer a lower cost of effort, but no specific knowledge is required to answer correctly. Furthermore, the task is very easy to understand and it does not carry any gender stereotype. ${ }^{5}$

\footnotetext{
${ }^{5}$ Both Belot and Schroeder (2013) using a physical version with real coins and Gioia (2016) using the same
} 
The Coin Task is always played in groups of two subjects and the rules for the payment determine our treatment conditions. Treated participants are in competition with their randomly determined opponent: the subject with the highest score gets 8 euro while the other one gets 2 euro. ${ }^{6}$ Participants in the Baseline receive the same monetary payoffs (one player 2 euro, the other 8 euro), which are however predetermined, so that there is no competition. Subjects are informed that they are randomly matched in pairs, and before playing the Coin Task they are also told whether their randomly determined reward is 2 or 8 euro. ${ }^{7}$ Monetary rewards in both treatments are conditional upon identifying at least 5 coins, otherwise the payoff is zero. We do so for the effort task to be perceived as incentivized in both conditions and therefore to avoid house-money effects (Kahneman et al., 1990, 1991; Thaler and Johnson, 1990). The chosen threshold is low in order to avoid the loss of observations in case subjects do not earn a positive amount.

The focus of our research is the pure effect of competition on subsequent risk-taking behaviour and therefore we want to avoid the possible confound represented by wealth effects, which may affect risk taking both in absolute and in relative terms. First, previous earnings can shape participants' willingness to take risks by cushioning the impact of bad outcomes in the BRET. For instance, higher earnings in the Coin Task could induce a more risk-seeking behaviour in the BRET and such an effect do not need to be linear. ${ }^{8}$ Minimizing the heterogeneity in the outcomes is therefore crucial, and this is the reason why we opt for fixed prizes in the tournament (either 2 or 8 euro), rather than for rewards that change at the margin with individual productivity. To be salient, however, competition needs to map into different outcomes for winners and losers and this leads to our second concern. Competition induces ex post inequality, thereby making relative earnings salient in models such as Fehr and Schmidt (1999) and Charness and Rabin (2002). Earning different amounts may affect decisions under risk via social comparison as shown by Fafchamps et al. (2015); Gamba et al. (2014); Linde and Sonnemans (2012), and Schmidt et al. (2015). However, inequality of earnings characterizes many payment schemes and is not a distinguishing feature of competition. For this reason we need a Baseline condition in which social comparison based on monetary outcomes is identical. In the Baseline subjects are randomly matched in pairs and receive the same rewards as in the tournament, but rewards are randomly assigned instead of determined by the relative performance. Our need to minimize the differences in earnings also explains why we did not choose a piece-rate scheme as a baseline. Thus, the comparison across conditions allows us to isolate the effect of competition on risk attitudes.

After the completion of the Coin Task, we elicit subjects' risk preferences by using the BRET (Crosetto and Filippin, 2013). The BRET is a simple risk elicitation method in which

computerized version as in our experiment show that the score of males and females does not significantly differ. Belot and Schroeder (2015) also use the physical version of the task. They do not report the scores by gender but they claim that women make significantly less mistakes.

${ }^{6}$ Possible ties are broken first looking at the total number of attempts, i.e. also including wrong answers in the score, and in case of a further tie at the time taken to identify the coins correctly.

${ }^{7}$ We let subjects learn their payoff before the Coin Task in the Baseline because the ex-post uncertainty about one's payoff is a distinguishing feature of competition due to the strategic uncertainty involved.

${ }^{8}$ For instance, Crosetto and Filippin (2013) show that earnings in previous tasks have a U-shape effect on subsequent choices in the BRET. The most risk averse choice follows a payoff of about 2 Euro, while higher and lower earnings are associated to more risk seeking decisions. 
participants see on their computer screen a field containing of 100 boxes, as shown in Figure 2. A subject has to choose how many boxes to collect knowing that 99 boxes contain 10 Euro cents while one contains a bomb that, if collected, destroys the earnings. Boxes are collected in numerical order starting from the top-left corner and ending at the box corresponding to participant's chosen number. The bomb can be in any box with the same probability and its position is randomly determined at the end of the experiment, i.e. after the choice is made, in order to avoid truncation of the data. The BRET allows to span the whole domain of risk preferences, with a risk neutral choice corresponding to 50 boxes. A higher (lower) choice identifies risk seeking (aversion). After selecting a number of boxes, subjects are informed about the lottery they are going to play. The chosen number of boxes is shown in light grey and the potential earnings and their corresponding probabilities are explicitly described. Participants may change their choice as many times as they like before confirming it.
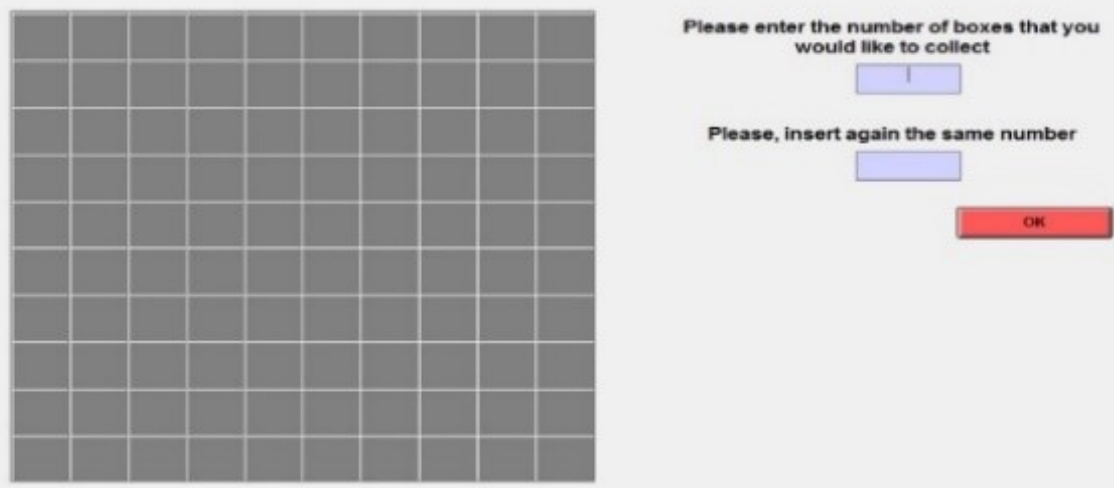

Figure 2: The Bomb Riks Elicitation Task

We elicit risk attitudes only once, after the effort task. The reason is that we want to avoid confounds such as hedging, possible violations of the Reduction Axiom, or even a roller coaster behaviour across subsequent choices.

Experimental Procedure. The experiment took place at the University of Milan in March 2016. It was programmed using z-Tree (Fischbacher, 2007). Subjects were recruited using the ORSEE software (Greiner, 2015) ensuring a balanced representation by gender.

Upon their arrival subjects entered the laboratory and were randomly assigned to computer terminals, separated by partitions. After reading aloud the instructions illustrating the Coin Task, participants were solicited to raise questions. Once all doubts had been privately dispelled, the first stage of the experiment began.

Participants were randomly matched in pairs and were given the chance to practice for one minute in order to familiarize with the Coin Task. Coins identified during this minute did not add to the final score. They had then five minutes to perform the incentivized task, which consisted in recognizing as many coins as possible. After the practice period subjects 
were asked to guess the number of coins they were going to correctly identify and whether this number was higher, equal, or lower than the average of the other participants. We ask these questions in order to elicit subjects' expectations and be able to build a proxy for overconfidence. ${ }^{9}$ At the end of the real effort task, subjects were told their own score and in the Competition treatment also the outcome of the tournament. Subjects were not told their peer's score.

The experimenter then read aloud the instructions of the BRET and participants were given again the opportunity to clear up any doubts individually. Subjects played the BRET and, after submitting their choice, completed a short questionnaire. The position of the bomb was then randomly determined at the individual level. Subjects were notified about their final earnings (2.5 euro of show-up fee, plus their earnings in both the Coin Task and the BRET), received their payment in a sealed envelope and left the laboratory.

\section{Results}

A total of 130 subjects took part in the experiment: 62 in the baseline and 68 in the competition treatment. Table 1 presents summary statistics of our main variables for the full sample and by treatment. The last column of the table reports the p-value of a MannWhitney test for the equality of the variables across conditions.

48 percent of all participants are females and they are on average 21 years old. Subjects in the two conditions are homogeneous in terms of individual characteristics such as gender, age and ability. Females represent 42 percent of subjects in the baseline and 53 percent of treated subjects but the difference is not statistically significant.

In order to perform the Coin Task subjects do not need any specific cognitive ability. A sufficient amount of effort is enough to get a correct answer. However, subjects endowed with higher levels of speed of thought, patience and ability to focus may be faster than other subjects and thus more likely to win. ${ }^{10}$ In order to control for the effect of differences in ability, in the final questionnaire we ask the average grade obtained over the first semester of the academic year (Average Grade). Grades range from 18 to 31 (30 cum laude) and participants report an average grade of 25.7 in the full sample. The average grade is 25.4 in the baseline and 26 in the treatment, not significantly different.

In what follows we present the results of our experiment starting from the real effort task, then moving on subjects' expectations and finally focusing on our main variable of interest, i.e. risk attitudes.

Coin task. A comparison of the performance in the Coin Task across treatments allows us to check the effectiveness of our incentive scheme. In the Baseline participants have to correctly identify only five coins in order to earn their payoff, while in the competition treatment their earnings also depend on their relative performance. Table 1 shows that competition improves subjects' performance, as expected, although figures are rather surprisingly of a

\footnotetext{
${ }^{9}$ We elicit subjects' beliefs before the incentivized task to better fit the definition of confidence as the belief about one's own ability. Given the nature of the task, an ex-post elicitation would have reduced to an assessment of the work done.

${ }^{10}$ Different knowledge of Euro Coins is not an issue in our dataset because all students have the Euro as national currency.
} 
Table 1: Summary statistics

\begin{tabular}{|c|c|c|c|c|c|c|c|}
\hline \multirow[b]{2}{*}{ Variable } & \multicolumn{2}{|c|}{ All } & \multicolumn{2}{|c|}{ Baseline } & \multicolumn{2}{|c|}{ Competition } & \multirow{2}{*}{$\begin{array}{c}\text { Mann-Wh } \\
\text { p-value }\end{array}$} \\
\hline & Mean & Std. Dev. & Mean & Std. Dev. & Mean & Std. Dev. & \\
\hline Female & 0.477 & 0.501 & 0.419 & 0.497 & 0.529 & 0.503 & 0.2113 \\
\hline Age & 21.238 & 3.142 & 21.177 & 2.440 & 21.294 & 3.686 & 0.8558 \\
\hline $\begin{array}{l}\text { Average Grade } \\
\text { Coin Task }\end{array}$ & 25.715 & 3.420 & 25.419 & 4.091 & 25.985 & 2.668 & 0.5923 \\
\hline Total Coins & 25.331 & 6.169 & 23.645 & 5.204 & 26.868 & 6.601 & 0.0048 \\
\hline Correct & 23.015 & 5.951 & 21.597 & 4.792 & 24.309 & 6.611 & 0.0035 \\
\hline $\begin{array}{l}\text { Wrong } \\
\text { Expectations }\end{array}$ & 2.316 & 3.196 & 2.048 & 3.07 & 2.559 & 3.312 & 0.0960 \\
\hline $\begin{array}{l}\text { Guessed Coins } \\
\text { Risk Behaviour }\end{array}$ & 13.862 & 7.210 & 12.935 & 6.563 & 14.706 & 7.704 & 0.2332 \\
\hline BRET choice & 41.369 & 17.029 & 43.452 & 19.018 & 39.471 & 14.878 & 0.3588 \\
\hline $\mathrm{N}$ & 130 & 62 & & 68 & & & \\
\hline
\end{tabular}

similar order of magnitude. Subjects in the Baseline try on average 23.6 coins, 21.6 of which are correctly identified. The corresponding figures are significantly higher when subjects perform the Coin Task in competition: the number of coins attempted on average is 26.8 with an average of 24.3 correct answers. ${ }^{11}$

As regards the gender dimension, we find that females perform significantly worse than males (Table 2), something at odds with previous evidence on the Coin Task. However, differences in the performance are significant both in the Baseline and in the Competition treatment and are of similar size. ${ }^{12}$ Hence, gender differences in competitiveness do not seem to play any role. ${ }^{13}$

Table 2: Performance in the Coin Task by Treatment and Gender

\begin{tabular}{lc|cc|c|c}
\hline \hline & All & Baseline & Competition & Difference & Mann-Whitney \\
\hline Males & 24.12 & 22.53 & 25.91 & 3.38 & $\mathrm{p}=0.008$ \\
Females & 21.81 & 20.31 & 22.89 & 2.58 & $\mathrm{p}=0.041$ \\
\hline Difference & 2.31 & 2.22 & 3.02 & & \\
\hline Mann-Whitney & $\mathrm{p}=0.027$ & $\mathrm{p}=0.080$ & $\mathrm{p}=0.035$ & & \\
\hline \hline
\end{tabular}

\footnotetext{
${ }^{11}$ The high performance in the Baseline condition can be rationalized by the fact that subjects dislike inactivity in the lab and tend to avoid it even at a cost such as exerting effort (see Jensenius, 2017, and references therein).

${ }^{12}$ Estimating a diff-in-diff model we find that the gender differences across conditions (0.8) do not statistically differ.

${ }^{13}$ Many studies have shown that the competitiveness of the environment may induce a gender gap in performance. Starting from Gneezy et al. (2003) this result has been largely replicated particularly in mixed-gender competition and using stereotypical male endeavours, such as solving mazes and math tasks (Shurchkov, 2012). Niederle (2016) also notes that not all the tasks are suitable to measure changes in performance under different incentive schemes. For instance, no change in performance is observed using the task of adding five two-digit numbers as in Niederle and Vesterlund (2007). This is likely the case of the Coin task, too, as a similar null effect of competition on performance across gender is also found by Gioia (2016).
} 
Expectations. Part of the literature on the gender gap in performance ascribes differences in competitive endeavours to overconfidence for males and underconfidence for females (Niederle and Vesterlund, 2007). In order to check whether confidence has explanatory power in our setting, before performing the effort task, we elicit subjects' expectations on their performance. We then use the difference between expected and realized score to measure their confidence, as commonly done in the literature on overconfidence (De Paola et al., 2014; Ifcher and Zarghamee, 2014). A negative number means that subjects are underconfident, as they identify more coins than what they expected. Viceversa, positive values indicate overconfidence.

Subjects in our sample are underconfident on average, as the mean of the Confidence variable is equal to -9.15 . Table 1 shows that the expected performance is lower than the actual one both in the Baseline $(12.9-21.6=-8.7)$ and in the Competition treatment (14.7 $24.3=-9.6)$. Confidence does not significantly differ either by treatment or by gender (Table 3).

Table 3: Confidence by treatment and by gender

\begin{tabular}{lc|lc}
\hline \hline & Confidence & & Confidence \\
\hline Baseline & -8.66 & Males & -9.79 \\
Competition & -9.60 & Females & -8.45 \\
\hline Difference & 0.94 & & -1.34 \\
\hline Mann-Whitney & $\mathrm{p}=0.291$ & \multicolumn{2}{c}{$\mathrm{p}=0.301$} \\
\hline \hline
\end{tabular}

As far as risk attitudes are concerned, a positive correlation emerges between confidence and the choice in the BRET (corr $=0.152, p=0.085$ ). Forecasts improve, i.e. a lower underconfidence is observed, in the risk seeking domain. This result is driven by the competition treatment (corr $=0.238, p=0.051$ ) while no correlation emerges for the baseline.

Although far from the observed performance on average, subjects' expectations in the effort task turn out to be quite reliable, as they significantly correlate with the actual performance. Rather surprisingly, the correlation is stronger in the Baseline (corr $=0.543, p<0.001$ ) than in the Competition (corr $=0.210, p=0.085$ ).

Risk attitudes. In this section we answer our main research question, namely whether competition affects risk attitudes, possibly in a different way along a gender perspective.

Table 1 reports the descriptive statistics of our main variables of interest and shows that on average subjects are risk averse in both conditions, and competition seems to increase risk aversion. Subjects in the Baseline collect about 43.5 boxes on average, while the corresponding figure for the treated is about 39.5, but the difference is not significant.

By comparing decisions of individuals who experienced competition with those of individuals ending up in the same financial situation without competing, our design allows us to control for wealth effects eliminating social comparison considerations. Our design also controls for everything related to the monetary consequences of the tournament, including the ex-ante uncertainty of the final outcomes, as well as what the payoffs trigger in terms of emotions or superstition. ${ }^{14}$ However, competition can affect risk attitudes over and

\footnotetext{
${ }^{14}$ Here by superstition we mean thoughts like "I have got the bad outcome, so I will be unlucky again" or
} 
above its monetary consequences through several channels (stress and fatigue, emotions, loss of control). Some of these determinants are not related to the competitive endeavour in general, but rather produce their effect through the outcomes of the tournament.

In Table 4 we report the average decision in the BRET separately by treatment and outcome. Data show a higher degree of risk aversion in both outcomes under competition as well as when facing a bad outcome in both treatments. However, none of the differences reaches traditional significance levels.

Table 4: Risk attitudes by treatment and outcome

\begin{tabular}{lcc|c|c}
\hline \hline & Bad Outcome & Good Outcome & Difference & Mann-Whitney \\
\hline Baseline & 42.23 & 44.68 & -2.45 & $\mathrm{p}=0.587$ \\
Competition & 38.21 & 40.74 & -2.53 & $\mathrm{p}=0.547$ \\
\hline Difference & 4.02 & 3.94 & & \\
\hline Mann-Whitney & $\mathrm{p}=0.385$ & $\mathrm{p}=0.385$ & & \\
\hline \hline
\end{tabular}

At first glance, competition does not seem to produce additional effects as compared to the Baseline condition. However, the gender dimension has been shown to be relevant in the literature about both competition and risk preferences. Hence, we split our sample by gender considering first the overall data by treatment (Table 5). We find that the slightly higher risk aversion previously found in Competition is driven by a potentially important effect for males, whose difference in the BRET choice (46.61 in the Baseline vs 39.25 in Competition) is quite large though not significant at conventional levels. In contrast, females' behaviour is not affected by the treatment.

Table 5: Risk attitudes by treatment and gender

\begin{tabular}{lcc|c|c}
\hline \hline & Males & Females & Difference & Mann-Whitney \\
\hline Baseline & 46.61 & 39.08 & 7.53 & $\mathrm{p}=0.136$ \\
Obs. & 36 & 26 & & \\
Competition & 39.25 & 39.67 & -0.42 & $\mathrm{p}=0.668$ \\
Obs. & 32 & 36 & & \\
\hline Difference & 7.36 & -0.59 & & \\
\hline Mann-Whitney & $\mathrm{p}=0.126$ & $\mathrm{p}=0.848$ & & \\
\hline \hline
\end{tabular}

Results with aggregate data may hide important effects that are outcome-dependent. Losers may become more risk averse if, for example, a bad outcome induces a shift in their locus of control. In contrast, winners may become more risk seeking if they think to be better able to beat the odds. Such effects can also be gender-specific, so in Table 6 we further break down the data both by gender and by outcome in the effort task.

By conditioning the gender analysis on the level of payoffs, we find that nothing emerges for females, whose average choice is rather stable across conditions and outcomes. In contrast, an interesting pattern emerges for males, who become significantly more risk averse

instead "I have been unlucky the first time, I will be lucky the second time". 
Table 6: Risk attitudes by treatment, gender and outcome

\begin{tabular}{lccc|ccc}
\hline \hline & \multicolumn{3}{c}{ Males } & \multicolumn{3}{c}{ Females } \\
\hline & $\begin{array}{c}\text { Bad } \\
\text { Outcome }\end{array}$ & $\begin{array}{c}\text { Good } \\
\text { Outcome }\end{array}$ & $\mathrm{M}-\mathrm{W}$ & $\begin{array}{c}\text { Bad } \\
\text { Outcome }\end{array}$ & $\begin{array}{c}\text { Good } \\
\text { Outcome }\end{array}$ & $\mathrm{M}-\mathrm{W}$ \\
\hline Baseline & 44.35 & 48.63 & $\mathrm{p}=0.407$ & 39.64 & 38.42 & $\mathrm{p}=0.980$ \\
Obs. & 17 & 19 & & 14 & 12 & \\
Competition & 35.14 & 42.44 & $\mathrm{p}=0.177$ & 40.35 & 38.81 & $\mathrm{p}=0.620$ \\
Obs. & 14 & 18 & & 20 & 16 & \\
M-W & $\mathrm{p}=0.058$ & $\mathrm{p}=0.183$ & & $\mathrm{p}=0.699$ & $\mathrm{p}=0.870$ & \\
\hline \hline
\end{tabular}

when losing the tournament as compared to receiving the low payoff in the Baseline. No statistically significant effect is instead observed when they win the tournament as compared to earning the same amount of money in the Baseline. ${ }^{15}$

Note that by focusing only on the choices after the tournament, one could be tempted to infer that males are affected by the outcome of the competition becoming more risk seeking after winning than after losing (42.44 vs. 35.14). However, the design of the experiment allows us to exclude that competition induces a more risk seeking behaviour for winners once wealth effects are taken into account. In other words, winners become relatively less risk averse than losers, but competition does not increase their risk tolerance as compared to subjects earning the same amount of money without competing. ${ }^{16}$

Our experiment has been envisaged with the primary goal of testing whether competition shapes risk attitudes while controlling in a clean manner that results are not driven by wealth effects. Consequently, our design is not equipped to empirically test the different determinants of such a relationship against each other. Nevertheless, our finding that competition affects the risk attitudes only for males losing the tournament is suggestive of the possible transmission mechanism. First, the results seem to exclude stress and fatigue, which should be driven by the strategic uncertainty and the higher effort exerted in the tournament, and should therefore characterize losers and winners alike. Second, an outcomedependent effect on risk attitudes looks consistent with emotions as the determinant, given that winning and losing trigger opposite feelings. However, the gender differences that we observe do not have a counterpart in the literature on emotions and risk attitudes. In particular, there is no evidence that females react significantly less than males (or not at all) to emotions. Therefore, we tend to exclude emotions as the explanatory variable, too. Lastly, our pattern of results is consistent with the literature on self-serving attribution. Competition is not a pure chance event because outcomes are also influenced by one's ability and effort. The self-serving attributional bias posits that individuals tend to make attributions for negative outcomes that are more external than for positive ones. Beisswingert et al. (2016)

\footnotetext{
${ }^{15}$ Given the low number of observations we cannot exclude a false negative across treatments in the Good Outcome case, but note that the point estimate goes in the opposite direction compared to what one might expect.

${ }^{16}$ Results of Table 6 are confirmed by diff-in-diff regressions including demographic controls, confidence and performance, reported in the Appendix. We find a statistically significant effect of competition only on males obtaining the bad outcome.
} 
show that a shift in the locus of control from internal to external determines an increase of risk aversion. ${ }^{17}$ Hence, losing the tournament may cause more risk-averse choices because of a shift in the locus of control. The gender differences in our results are also consistent with the literature on self-serving attribution. Deaux and Farris (1977) were the first showing that males are more prone than females to such a bias, a result confirmed in adulthood by several studies, as described in the meta-analysis byMezulis et al. (2004). This finding helps rationalizing why we observe an increase in risk aversion after losing the tournament only for males.

Losing may reduce the extent to which males believe that they can predict or influence future events and this may, in turn, increase their risk aversion. Therefore, a negative outcome may have an effect even stronger for males who perform better. The reason is that losing despite an effective completion of the effort task may induce a stronger shift in the locus of control. Indeed, we find that the higher the performance in the Coin task of males losing the competition, the lower their choice in the BRET (corr $=-0.632, p=0.015$ ), i.e. the higher their risk aversion. We are aware that a possible reverse causality link may exist between the two variables, as a higher risk aversion may simply induce to optimally choose a higher level of effort in the Coin task. If purely endogenous, however, such a relationship should hold in general, while we observe it only for males losing the tournament. Figure 3 shows that a negative correlation between the choice in the BRET and performance in the Coin task does not characterize males who win the tournament (left hand panel). ${ }^{18}$ Since one could argue that this comparison is made difficult by a different average performance, the right hand panel compares all the subjects losing the tournament, showing that females' choices under risk are not related to their performance.

Table 7 provides an econometric representation of the same fact. Choices under risk negatively correlate with the performance in the Coin Task only for males losing the tournament, even in a multivariate framework controlling for the degree of confidence and ability. ${ }^{19}$

Further suggestive evidence that the relationship highlighted above is genuine can be derived in Gioia (2016), who elicits risk attitudes also before the Coin Task, without finding any significant correlation between risk attitudes ex-ante and performance in the competitive endeavour.

\section{Conclusion}

Competition is important in a wide range of economic decisions, and this paper contributes to the literature by analysing the consequence of being exposed to competitive

\footnotetext{
${ }^{17}$ Beisswingert et al. (2016) propose a computer game in which participants have to predict where an object would be displayed on a circle by recognizing the systematic pattern underlying the previously displayed objects. They show that manipulating the degree of difficulty of the task has an effect in shifting the locus of control, inducing significantly more risk averse choices in the Devil's task (Slovic, 1966), a risk elicitation method that shares many features with the BRET used in our experiment.

${ }^{18}$ When we restrict the observations to the performance range where we observe both males winning and males losing, we still find evidence of a negative relationship between performance and risk seeking behaviour for males losing and we find a weakly positive relationship for males winning the tournament.

${ }^{19}$ Results in columns (1) and (2) are robust when we restrict the observations to the performance range where we observe both males winning and males losing the competition.
} 


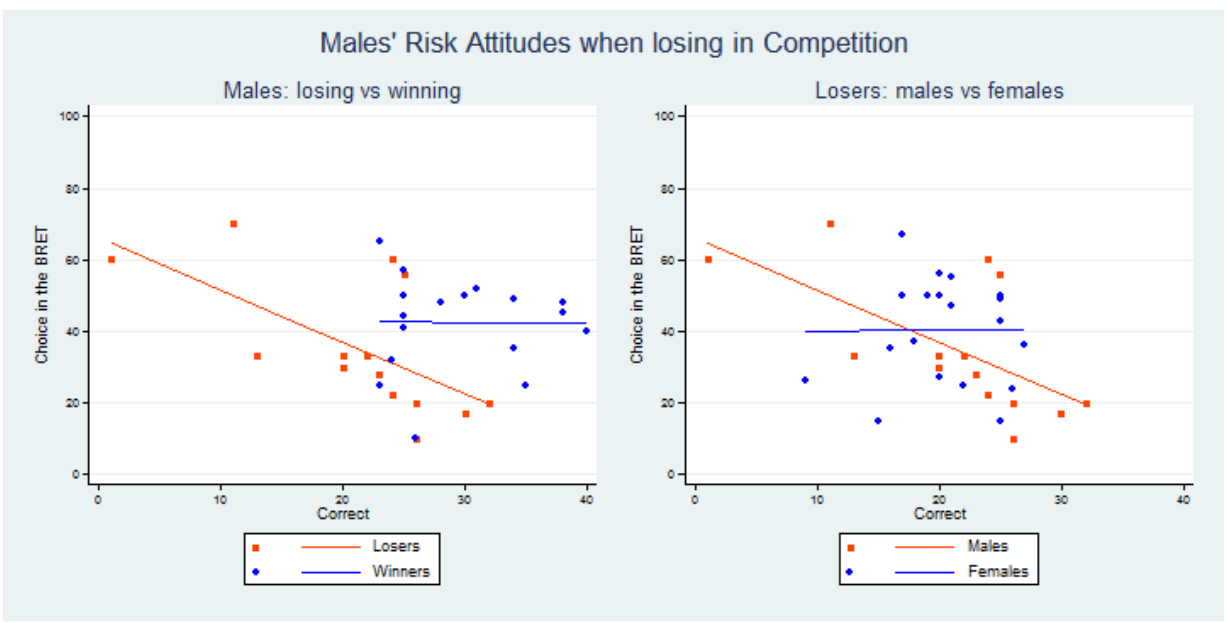

Figure 3: Males' Risk Attitudes when losing in Competition

environments on subsequent individual risk-taking behaviour. The economics literature typically evaluates relative performance pay schemes only through their direct impact on productivity. However, competition is seldom a one-shot phenomenon, as individuals face many situations involving competitive pressure and make relevant decisions even after competition is over. Therefore, besides short-run effects on performance, competitive pressure may induce other effects that can affect subsequent decisions adding to its long run impact. From this point of view risk attitudes are a natural candidate as a transmission mechanism.

We investigate the causal effect of competition on subsequent risk-taking behaviour by running a lab experiment eliciting the risk attitudes of a sample of subjects that have performed a real effort task exogenously manipulated in terms of the degree of competitiveness. We find that, overall, treated subjects display a more risk-averse behaviour. However, such a positive relationship between competition and risk aversion is not statistically significant, even conditioning on the outcome of the tournament. We devote particular attention to the analysis of the effects across gender because several studies find that women differ from men in terms of both risk aversion and fondness for competition. Indeed, we find a novel and counter-intuitive result: while females' behaviour is stable across treatments and outcomes, males become more risk averse after losing in the competitive environment. There is instead no evidence of a symmetric more risk-seeking behaviour after winning the tournament.

The design of the experiment carefully controls for wealth effects and any other payoffrelated determinants, thereby isolating the pure effect of competition at the individual level and excluding social comparison considerations. We interpret our findings in terms of males' reaction to negative outcomes driven by intrinsic motives. The most plausible explanation is that the negative outcome induces a shift in the locus of control from internal to external. Losing the tournament reduces the extent to which males believe that they can predict or influence future events and this, in turn, increases their risk aversion. In other words, when losing in a competitive task males may have an inclination to project their inability to control events even on subsequent decisions involving merely random outcomes. Our explanation is consistent with previous findings in the literature that a shift in the locus 
Table 7: Risk attitudes and Performance in Competition

\begin{tabular}{|c|c|c|c|c|}
\hline & \multicolumn{4}{|c|}{ BRET choice } \\
\hline & \multicolumn{2}{|c|}{ Males } & \multicolumn{2}{|c|}{ Losers } \\
\hline & (1) & (2) & (3) & (4) \\
\hline \multirow[t]{2}{*}{ Correct(Male,lose) } & $-1.4602^{* * *}$ & $-1.7035^{* * *}$ & $-1.4602^{* * *}$ & $-1.6214^{* * *}$ \\
\hline & $(0.3795)$ & $(0.5124)$ & $(0.3779)$ & $(0.4522)$ \\
\hline \multirow[t]{2}{*}{ Correct(Male,win) } & -0.0323 & -0.2047 & & \\
\hline & $(0.5304)$ & $(0.6595)$ & & \\
\hline \multirow[t]{2}{*}{ Winner } & -22.7209 & -25.9121 & & \\
\hline & $(19.7591)$ & $(18.7123)$ & & \\
\hline \multirow[t]{2}{*}{ Correct(Female,lose) } & & & 0.0137 & 0.1973 \\
\hline & & & $(0.7969)$ & $(0.6751)$ \\
\hline \multirow[t]{2}{*}{ Female } & & & -26.0464 & $-31.9327^{*}$ \\
\hline & & & (19.0715) & $(17.9474)$ \\
\hline \multirow[t]{2}{*}{ Confidence } & & -0.1983 & & -0.0884 \\
\hline & & $(0.3014)$ & & $(0.2696)$ \\
\hline \multirow[t]{2}{*}{ Ability } & & 1.5852 & & $2.9573^{* * *}$ \\
\hline & & $(1.1964)$ & & $(0.8325)$ \\
\hline \multirow[t]{2}{*}{ Constant } & $66.1194^{* * *}$ & $71.0617^{* * *}$ & $66.1194^{* * *}$ & $68.2202^{* * *}$ \\
\hline & $(8.7244)$ & $(10.3456)$ & $(8.6880)$ & $(8.9368)$ \\
\hline Observations & 32 & 32 & 34 & 34 \\
\hline Adjusted $R^{2}$ & 0.208 & 0.219 & 0.157 & 0.301 \\
\hline
\end{tabular}

Heteroskedastic-robust standard errors in parentheses

${ }^{*} p<0.10,{ }^{* *} p<0.05,{ }^{* * *} p<0.01$

The difference in the effect of Correct for Winner and Loser in the subsample of males is always significant at the 5\% level (columns 1 and 2). The difference in the effect of Correct for Male and Female in the subsample of losers has $p$-value $=0.105$ in column 3 and is significant at the $5 \%$ level in column 4 .

of control causes an increase of risk aversion and that males are more prone to the selfserving attributional bias. Identifying in a controlled manner the ultimate cause why losing a competitive endeavour increases males' risk aversion goes beyond the scope of this paper, but we believe that it constitutes an interesting goal for future research. 


\section{References}

Apicella, C. L., Demiral, E. E., Mollerstrom, J., May 2017. No gender difference in willingness to compete when competing against self. American Economic Review 107 (5), 136-40.

Apicella, C. L., Dreber, A., Mollerstrom, J., 2014. Salivary testosterone change following monetary wins and losses predicts future financial risk-taking. Psychoneuroendocrinology 39, $58-64$.

Beisswingert, B. M., Zhang, K., Goetz, T., Fischbacher, U., 2016. Spillover effects of loss of control on risky decision-making. PloS one 11 (3), e0150470.

Böheim, R., Lackner, M., 2013. Gender and competition: Evidence from jumping competitions.

Booth, A. L., Nolen, P., 2012. Gender differences in risk behaviour: does nurture matter?*. The Economic Journal 122 (558), F56-F78.

Botchway, E., 2018. Economic preferences and adaptation to natural risk: Experimental evidence from ghana. Phd dissertation.

Buckert, M., Schwieren, C., Kudielka, B. M., Fiebach, C. J., 2015. How stressful are economic competitions in the lab? an investigation with physiological measures. Discussion Paper Series 593, University of Heidelberg.

Bull, C., Schotter, A., Weigelt, K., 1987. Tournaments and piece rates: An experimental study. Journal of political Economy 95 (1), 1-33.

Buser, T., 2016. The impact of losing in a competition on the willingness to seek further challenges. Management Science.

URL http://dx.doi.org/10.1287/mnsc.2015.2321

Buser, T., Niederle, M., Oosterbeek, H., 2014. Gender, competitiveness, and career choices. The Quarterly Journal of Economics 129 (3), 1409-1447.

Cameron, L., Shah, M., 2015. Risk-taking behavior in the wake of natural disasters. Journal of Human Resources $50(2), 484-515$.

Campos-Vazquez, R. M., Cuilty, E., 2014. The role of emotions on risk aversion: A prospect theory experiment. Journal of Behavioral and Experimental Economics 50,1 - 9 .

Cerin, E., Barnett, A., 2006. A processual analysis of basic emotions and sources of concerns as they are lived before and after a competition. Psychology of Sport and Exercise 7 (3), 287 - 307.

Charness, G., Rabin, M., 2002. Understanding social preferences with simple tests. Quarterly Journal of Economics 117 (3), 817-69.

Conte, A., Levati, M. V., Nardi, C., Oct. 2013. The Role of Emotions on Risk Preferences: An Experimental Analysis. Jena Economic Research Papers 2013-046, Friedrich-Schiller-University Jena.

Crosetto, P., Filippin, A., August 2013. The 'bomb' risk elicitation task. Journal of Risk and Uncertainty 47 (1), 31-65.

Croson, R., Gneezy, U., June 2009. Gender Differences in Preferences. Journal of Economic Literature 47 (2), $448-74$

De Paola, M., Gioia, F., Scoppa, V., 2014. Overconfidence, omens and gender heterogeneity: Results from a field experiment. Journal of Economic Psychology 45, 237-252.

Deaux, K., Farris, E., 1977. Attributing causes for one's own performance: The effects of sex, norms, and outcome. Journal of Research in Personality 11 (1), 59 - 72.

Deck, C., Jahedi, S., 2015. The effect of cognitive load on economic decision making: A survey and new experiments. European Economic Review 78, 97-119. 
Drichoutis, A. C., Nayga Jr, R. M., 2013. Eliciting risk and time preferences under induced mood states. The Journal of Socio-Economics 45, 18-27.

Eckel, C. C., El-Gamal, M. A., Wilson, R. K., 2009. Risk loving after the storm: A Bayesian-Network study of Hurricane Katrina evacuees. Journal of Economic Behavior \& Organization 69 (2), 110-124.

Eckel, C. C., Grossman, P. J., 2008. Men, Women and Risk Aversion: Experimental Evidence. Vol. 1 of Handbook of Experimental Economics Results. Elsevier, Ch. 113, pp. 1061-1073.

Fafchamps, M., Kebede, B., Zizzo, D. J., 2015. Keep up with the winners: Experimental evidence on risk taking, asset integration, and peer effects. European Economic Review 79, 59 - 79.

Fehr, E., Schmidt, K. M., 1999. A theory of fairness, competition, and cooperation. Quarterly journal of Economics, 817-868.

Filippin, A., Crosetto, P., 2016. A reconsideration of gender differences in risk attitudes. Management Science forthcoming.

Fischbacher, U., 2007. z-tree: Zurich toolbox for ready-made economic experiments. Experimental Economics $10(2), 171-178$.

Gamba, A., Manzoni, E., Stanca, L., 2014. Social comparison and risk taking behavior. Working Papers 266.

Gill, D., Prowse, V., 2014. Gender differences and dynamics in competition: The role of luck. Quantitative Economics 5 (2), 351-376.

Gillen, B., Snowberg, E., Yariv, L., 2015. Experimenting with measurement error: Techniques with applications to the caltech cohort study. Tech. rep., National Bureau of Economic Research.

Gioia, F., 2016. Incentive schemes and peer effects on risk behaviour: an experiment. Mimeo.

Gneezy, U., Niederle, M., Rustichini, A., 2003. Performance in competitive environments: Gender differences. The Quarterly Journal of Economics 118 (3), 1049-1074.

Greiner, B., 2015. Subject pool recruitment procedures: organizing experiments with orsee. Journal of the Economic Science Association 1 (1), 114-125.

Haenni, S., 2016. Do Setbacks Delay the Participation in Repeated Competitions? Evidence from a Natural Experiment with Amateur Tennis Players. mimeo.

Ifcher, J., Zarghamee, H., 2014. Affect and overconfidence: A laboratory investigation. Journal of Neuroscience, Psychology, and Economics 7 (3), 125.

Jensenius, John Spaulding, I., 2017. On Inactivity in the Lab. Phd dissertation.

Kahneman, D., Knetsch, J. L., Thaler, R. H., 1990. Experimental tests of the endowment effect and the coase theorem. Journal of political Economy, 1325-1348.

Kahneman, D., Knetsch, J. L., Thaler, R. H., 1991. Anomalies: The endowment effect, loss aversion, and status quo bias. The journal of economic perspectives 5 (1), 193-206.

Kräkel, M., 2008. Emotions in tournaments. Journal of Economic Behavior \& Organization 67 (1), $204-214$.

Lane, T., 2017. How does happiness relate to economic behaviour? a review of the literature. Journal of behavioral and experimental economics $68,62-78$.

Lerner, J. S., Keltner, D., 2001. Fear, anger, and risk. Journal of personality and social psychology 81 (1), 146.

Linde, J., Sonnemans, J., 2012. Social comparison and risky choices. Journal of Risk and Uncertainty 44 (1), $45-72$. 
Mezulis, A. H., Abramson, L. Y., Hyde, J. S., Hankin, B. L., 2004. Is there a universal positivity bias in attributions? a meta-analytic review of individual, developmental, and cultural differences in the self-serving attributional bias. Psychological bulletin 130 (5), 711.

Niederle, M., 2016. Gender. In: Kagel, J., Roth, A. E. (Eds.), Handbook of Experimental Economics.

Niederle, M., Vesterlund, L., 2007. Do women shy away from competition? do men compete too much? The Quarterly Journal of Economics 122 (3), 1067-1101.

Niederle, M., Vesterlund, L., 2011. Gender and competition. Annu. Rev. Econ. 3 (1), 601-630.

Saccardo, S., Pietrasz, A., Gneezy, U., 2017. On the size of the gender difference in competitiveness. Management Science forthcoming.

Schmidt, U., Friedl, A., Lima de Miranda, K., 2015. Social comparison and gender differences in risk taking. Kiel Working Papers 2011, Kiel Institute for the World Economy (IfW).

Shurchkov, O., 2012. Under pressure: gender differences in output quality and quantity under competition and time constraints. Journal of the European Economic Association 10 (5), 1189-1213.

Slovic, P., 1966. Risk-Taking in Children: Age and Sex Differences. Child Development 37 (1), 169-176.

Starcke, K., Brand, M., 2012. Decision making under stress: a selective review. Neuroscience \& Biobehavioral Reviews 36 (4), 1228-1248.

Thaler, R. H., Johnson, E. J., 1990. Gambling with the house money and trying to break even: The effects of prior outcomes on risky choice. Management science 36 (6), 643-660.

van Veldhuizen, R., 2016. Gender differences in tournament choices: Risk preferences, overconfidence or competitiveness? WZB Discussion Paper SP II 2016-207.

Vugt, M. v., Cremer, D. D., Janssen, D. P., 2007. Gender differences in cooperation and competition: The malewarrior hypothesis. Psychological science 18 (1), 19-23.

Zhong, S., Shalev, I., Koh, D., Ebstein, R. P., Chew, S. H., 2016. Competitiveness and stress.

URL https://ssrn.com/abstract=2717459 or http://dx.doi.org/10.2139/ssrn .2717459 


\section{Appendix}

This appendix shows the results of a diff-in-diff analysis studying gender differences in risk preferences by conditioning on both treatment and outcome. The first two regressions are estimated in the subsample of males and the last two in the subsample of females. In columns (1) and (3) we include demographic controls while in columns (2) and (4) we also control for confidence and performance. As shown in Table 6, we find a statistically significant effect of competition only on males obtaining the bad outcome.

Table 8: Risk attitudes by treatment, gender and outcome

\begin{tabular}{lcccc}
\hline \hline & \multicolumn{3}{c}{ Males } & \multicolumn{2}{c}{ Females } \\
& $(1)$ & $(2)$ & $(3)$ & $(4)$ \\
\hline Good Outcome & 2.4033 & 1.8906 & -1.4126 & -1.0227 \\
& $(7.0986)$ & $(7.1134)$ & $(6.0023)$ & $(6.1915)$ \\
Competition (bad outcome) & $-13.4517^{* *}$ & $-15.6164^{* *}$ & 0.3861 & 0.4111 \\
& $(5.8219)$ & $(6.0613)$ & $(6.0653)$ & $(5.9180)$ \\
Competition (good outcome) & -4.7033 & -4.0754 & -0.0532 & 0.9294 \\
& $(6.6430)$ & $(7.3852)$ & $(4.9209)$ & $(6.1709)$ \\
Age & $1.4107^{* * *}$ & $1.5177^{* * *}$ & -1.5833 & -1.6300 \\
& $(0.4148)$ & $(0.4600)$ & $(1.0481)$ & $(0.9871)$ \\
Ability & -0.2947 & -0.7596 & -0.2209 & -0.3795 \\
Correct & $(1.1719)$ & $(1.0949)$ & $(0.4231)$ & $(0.4693)$ \\
Confidence & & 0.2534 & & 0.2878 \\
& & $(0.5372)$ & & $(0.5155)$ \\
Constant & & $0.5393^{*}$ & & 0.5285 \\
& & $(0.2724)$ & & $(0.3372)$ \\
\hline Observations & 22.6972 & 32.2217 & $78.0672^{* * *}$ & $80.7899^{* * *}$ \\
Adjusted $R^{2}$ & $68.8898)$ & $(32.5978)$ & $(25.7152)$ & $(23.9948)$ \\
\hline \hline
\end{tabular}

Heteroskedastic-robust standard errors in parentheses

${ }^{*} p<0.10,{ }^{* *} p<0.05,{ }^{* * *} p<0.01$ 


\section{Instructions}

\section{Translation from the original version in Italian}

Welcome. Thank you very much for agreeing to participate in today's experiment. From now on, we kindly ask you to remain silent and to turn off your mobile phones. Participants violating the rules will be asked to leave the experiment and will not receive additional payment.

The purpose of this experiment is the analysis of economic decision making. The instructions will be read aloud and will also appear on your screen. Please read the instructions carefully as your decisions will affect your earnings. Press the button 'OK' only when you have finished reading the instructions to go ahead with the experiment.

The experiment will last for about one hour. It consists of two parts. The experiment ends with a short questionnaire after which you will see your final earnings on your screen.

Your earnings are directly calculated in Euro. You will receive your earnings at the end of the experiment, after completing the questionnaire.

If you have any questions or problems, please raise your hand and one of the experimenters will come at your desk and answer your questions in private.

We recommend you not to discuss the experiment with other students after leaving the laboratory.

Please, press the button 'OK' to go ahead with the experiment.

\section{PART I}

This task consists in recognizing the value and the country of Euro coins.

On the left hand side of your computer screen you will see a table with different Euro coins and for each coin the indication of the value and of the country. A Euro coin randomly drawn from the table will appear on the right hand side of your screen.

You have to look for the corresponding coin in the table and then choose the value and the country.

You have to validate your answer by pressing the button 'Confirm'. Then, a new table and a new coin to identify will appear on your computer screen.

You have five minutes to recognize as many coins as you like.

Your score will correspond to the number of coins that you successfully recognize within this five-minute time period. There is no penalty for wrong answers.

\section{Baseline Treatment only}

In this task you may earn either $€ 8$ or $€ 2$. The computer will randomly divide you into pairs and it will randomly assign earnings. One component of the pair will earn $€ 8$ and the other will earn $€ 2$. The condition to fulfill in order to receive your earnings in this task is to correctly identify the value and the country of at least 5 coins.

At the end of the instructions and before starting the task you will be informed on your earnings. At the end of the task, you will be informed on your score. 


\section{Competition Treatment only}

Your earnings in this task depends both on your performance and on the performance of a randomly drawn participant in this room. You two will be in competition in this task. The winner is the person that correctly identifies more coins within the pair. This person will earn $€ 8$. The person who loses this competition will earn $€ 2$. In case of ties, we will consider the total number of attempts (that is we will consider also the coins that you have not identified correctly) and the winner will be the person who, given the same correct answers, will have attempted more coins.

The condition to fulfill in order to receive your earnings in this task is to correctly identify the value and the country of at least 5 coins. At the end of the task, you will be informed on your score and on the outcome of the competition.

\section{Both treatments}

Before we start, you are given the chance to practice for a minute in order to get familiar with the task. The number of coins correctly identified during this period will not affect your earnings.

At the end of the practice period, we will ask you how many coins do you think you will correctly identify during the five-minute period and if you think that the participants in this room will correctly identify on average more, the same or less coins than yourself.

Then, the five-minute period of the real experimental task will start.

Please, press the button 'OK' to proceed with the experiment.

\section{PART II}

In this part of the experiment you will see a field on your computer screen, which consists of 100 boxes, as shown in the picture below.

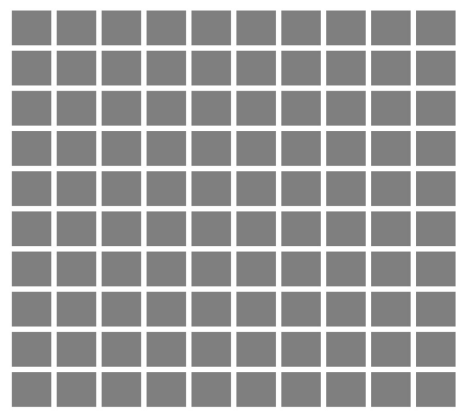

Your task is to choose how many boxes to collect. So you will be asked to choose a number between 1 and 100. Boxes will be collected in numerical order as shown in the video that you will see after pressing the button 'OK'.

\section{Video}

You will earn $€ 0.10$ for every box that you collect. Such earnings are only potential, however, because behind one of these boxes hides a bomb that, if collected, destroys all earnings accumulated. The bomb can be in any place with equal probability. 
At the end of the experiment, the computer will randomly determine, for each of you, the number of the box containing the bomb. When you will receive your earnings, if you want, you may see a table with the numbers drawn, to make sure that the position of the bomb was indeed randomly determined.

If your chosen number is greater than, or equal to, the number of the box containing the bomb, it means that you have collected the bomb. In this case, you will earn nothing in this task. In contrast, if your chosen number is smaller than the number of the box containing the bomb, it means that you did not collect the bomb. In this case, you will earn $€ 0.10$ for each box collected.

You have to write your chosen number twice. After pressing the button 'Continue' you will see information about your potential earnings. The boxes that you are collecting will be coloured in light grey. You can change your choice by pressing the button 'Change' or validate your answer by pressing the button 'Confirm'.

Please, press the button ' $\mathrm{OK}$ ' to proceed with the experiment. 